\title{
Diagnostic Accuracy of Transthoracic Ultrasound Guided Biopsy Versus Medical Thoracoscopic Pleural Biopsies in Unexplained Exudative Pleural Effusions in El-Minia University Hospital (Single Center Experience)
}

Bahaa Ibrahim Mohamed*1, Mostafa Ibrahim Ali Elshazly², Hala Abd-Elhameed Mohammad ${ }^{1}$, Ali Abdelazeem Hasan ${ }^{3}$, Ahmed Fathy Mady ${ }^{1}$

${ }^{1}$ Department of Chest Diseases, Faculty of Medicine Minia, University, ${ }^{2}$ Department of Chest Diseases, Faculty of Medicine, Cairo University, ${ }^{3}$ Department of Chest Diseases, Faculty of Medicine, Assiut University, Egypt

*Corresponding Author: Bahaa Ibrahim Mohamed, Mobile: +20 01142741126, Email: Mahmoud.znaty@ yahoo.com

\begin{abstract}
Background: Transthoracic ultrasound (TUS) has been established to be important in chest diseases including pleural diseases. Interventional pulmonology showed rapid growth and flex-rigid thoracoscopy development, which brought medical thoracoscopy to the forefront.

Objective: To compare the diagnostic accuracy, advantages and complications of TUS pleural biopsies versus medical thoracoscopic pleural biopsies in patients with idiopathic and exudative pleural effusion (PE) in El-Minia University Hospital.

Patients and methods: Seventy patients with idiopathic and exudative PE were divided randomly into two groups; group I included 45 patients underwent sonar guided pleural biopsy and group II involved 25 patients underwent thoracoscopic pleural biopsy.
\end{abstract}

Results: TUS-guided biopsy was diagnostic in 40 of 45 (88.8\%) compared to 24 of 25 cases (96\%) were diagnosed by thoracoscopy. Forty-two patients had malignant cause of effusion; 23 patients (51\%) in TUS group and $19(76 \%)$ patients in thoracoscopy group. Twenty-two patients had nonmalignant pleural effusion; 17 in group I and 5 in group II. The diagnosis was unclear in 6 patients, 5 of them in group I. Thoracoscopic group displayed greater percentages of post-procedural complications especially pain in site of puncture.

Conclusion: TUS examination has close sensitivity and specificity to medical thoracoscopy and allows better assessment of effusion with fewer complications.

Keywords: Sonar-guided biopsies, Medical thoracoscopy, Pleural diseases, Pleural effusion, Thoracic ultrasound.

\section{INTRODUCTION}

Pleural effusions (PE) are encountered conditions commonly seen in pulmonary medicine. Approximately 1.5 million new cases of pleural effusions are identified and around 180.000 thoracentesis are annually carried out in the United States alone ${ }^{(\mathbf{1}, 2)}$. Definitive or more accurate diagnosis in $59 \%$ to $73 \%$ of cases is provided by thoracocentesis and additional diagnostic methods are often needed ${ }^{(3}$, 4). Sometimes, it is difficult to find pleural effusion cause, particularly malignant $\mathrm{PE}$, via thoracocentesis alone due to relatively low the diagnostic accuracy ${ }^{(5-}$ 7). The important step when identifying PE is exanimation of pleural biopsy. Different techniques are used to obtain diagnostic tissues for histological examination such as local anesthetic thoracoscopy (LAT), image-guided biopsy and video-assisted thoracic surgery (VATS) ${ }^{(8-10)}$.

Ultrasound (US) examination has been found to be important in a wide range of chest diseases, especially when the pleural space is affected ${ }^{(3)}$. The benefits of ultrasound-guided biopsy are specifically rapid and cheap and is linked with a low incidence of pneumothorax (11). The diagnostic exactness and accuracy of US-guided needle biopsy (PCNB) in many literatures is $62.8 \%$ to $94 \%{ }^{(12-15)}$.
Recently, interventional pulmonology shows rapid growth along with the sedation techniques evolution and flex-rigid thoracoscopy development, which brought medical thoracoscopy (MT) to the forefront. Broadly, thoracoscopy is classified into minimally invasive MT and surgical thoracoscopy, which is called VATS ${ }^{(\mathbf{4}, \mathbf{1 6})}$. Relatively, MT is a safe procedure with a very low mortality rate. Empyema, bleeding, local metastasis, pneumothorax, bronchopleural fistula as well as pneumonia are major complications have been occurred in about $1.8 \%$. Whereas subcutaneous emphysema, minor bleeding, skin site infection, hypotension, atrial fibrillation, and fever are minor complications have been occurred in $7.3 \%$ according to the recent BTS guideline of Pleural Disease $^{(9)}$.

Our study aimed to compare the diagnostic accuracy, advantages and complications of TUS pleural biopsies versus medical thoracoscopic pleural biopsies in patients with idiopathic and exudative pleural effusion in El-Minia University Hospital.

\section{PATIENTS AND METHODS}

Seventy patients with idiopathic exudative pleural effusion who attendant to Chest and Tuberculosis Department, El-Minia University Hospital. 
Cairo University. All patients were enrolled in the study after written informed consent.

\section{The patients were classified in two groups:}

Group I: Forty-Five patients underwent sonar-guided pleural biopsy.

Group II: Twenty-Five patients underwent thoracoscopic pleural biopsy.

Inclusion criteria: Patients with unknown and exudative PE according to Light's criteria ${ }^{\left({ }^{17}\right)}$ for which a final diagnosis could not be made by cytological, bacteriological and chemical methods.

Exclusion criteria: Instable cardiovascular disease. Uncooperative patient. Bleeding abnormalities in international normalized ratio (INR) or platelets or use of anticoagulants during the procedure. Pneumonectomy of the other lung. Borderline lung failure and patients on mechanical machines. Severe cases of chronic obstructive pulmonary disease (COPD). Pyogenic skin lesions. In addition, extensive pleural adhesions is a relative contraindication to do medical thoracoscopy.

\section{The following was done for all patients:}

Full and detailed history and clinical examination were done for all patients.

\section{Investigations:}

Laboratory investigations included (1) Complete blood picture, which was determined by automated cell counter. (2) Coagulation profile (including prothrombin time, concentration and INR). (3) Liver and renal functions were assessed using fully automated clinical chemistry auto-analyzer. (4) Collagen profile (including ANA, Anti Ds DNA, R.F and ANCA).

Radiological investigations: (1) Chest X-ray (postroanterior) before and after the procedure. (2) Chest computed tomography (CT) with contrast was used to detect the following: (a) Pleural nodules (lesions less than $3 \mathrm{~cm}$ in largest diameter) or pleural masses (lesions more than $3 \mathrm{~cm}$ in largest diameter). (b) Pleural effusion. (c) Degree of pleural fluid. (3) Ultrasound with color Doppler (using PHILIPS, Clear Vue 350, Release2.0.6. Andover, MA01810USA). All cases were examined with curvilinear transducer probe $(\mathrm{C} 5-2 \mathrm{MHz})$ and linear array transducer probe (L12-4 $\mathrm{MHz}$.

Firstly, the entire patient's chest was screened using the low frequency curvilinear probe $(\mathrm{C} 5-2 \mathrm{MHz})$ for: (a) Detection of pleural effusion and pattern of effusion (free or loculated). (b) Detecting the size of the effusion.

Then, the entire patient's chest was screened using the high frequency linear probe $(\mathrm{L} 12-4 \mathrm{MHz})$ for detection of pleural thickness and pleural nodules (lesions $<3 \mathrm{~cm}$ in largest diameter) or pleural masses (lesions $>3 \mathrm{~cm}$ in largest diameter).
Thoracocentesis Sonar-guided: $500 \mathrm{cc}$ pleural fluid aspirated from the patient was subjected for full chemical, bacteriological and cytological examination.

Closed pleural biopsy using Tru-cut needle biopsy: For group I (US-guided) biopsies, the site of biopsy was identified and all biopsies were prepared using semi-automatic Tru-cut needle under guidance of TUS. By using a 18 gauge cutting needle three Tru-cut needle biopsies were obtained then the samples were preserved in formalin and normal saline till the time of histopathological examination ${ }^{(\mathbf{1 8})}$.

Thoracoscopic examination of the pleural cavity: Twenty-Five patients with idiopathic PE, MT biopsies were done by using KARL-STORZ rigid thoracoscopy with a good light source. The single-entry technique for medical thoracoscopy was carried out in all cases. The site of puncture was located in the mid- axillary area between the 4th and 6th intercostal spaces. The point of entry was selected depending on the site of dullness ${ }^{(9)}$ and pre-medical thoracoscopy by TUS examination to detect the best site of entry. Multiple biopsies were obtained under vision from suspected sites on parietal or diaphragmatic pleurae. All pleural biopsies were transferred to histopathological examination.

\section{Statistical analysis}

Data were statistically described in terms of mean \pm standard deviation (SD) and percentages when appropriate. Student $t$ test for independent samples was used for comparison of numerical variables between the study groups and Mann-Whitney $U$ test for independent samples. Comparison within a group of numerical variables was done using paired $t$ test. Chisquare $\left(\mathrm{v}^{2}\right)$ test was performed for comparing categorical data. Accuracy was represented using the terms sensitivity and specificity. When $p$ value $\leq 0.05$ was significant. SPSS PC program (Statistical Package for the Social Science; SPSS Inc., Chicago, IL, USA) release 20 for Microsoft Windows (2006) was used in all statistical calculation.

\section{RESULTS}

Our study included 70 patients who attendant to Chest Department of Minia University Hospital who fulfilled the inclusion criteria. The studied patients were classified into two groups; Group I: Forty-Five patients underwent sonar-guided pleural biopsy (29 males and 16 females with a mean age of $53.1 \pm 19.1$ years). 23 patients were malignant and 19 patients nonmalignant. Group II: Twenty-Five patients were subjected to thoracoscopic pleural biopsy (17 males and 8 females with a mean age of $59.5 \pm 16.3$ years). 17 patients were diagnosed malignancy and 5 patients had non-malignant conditions (Tables 1 \& 4 ). Diagnosis couldn't be done in 6 patients, five of them in group 1 . 
Table (1): Comparative statistical analysis between demographic data of group I and group II

\begin{tabular}{|c|c|c|c|c|}
\hline & & Group I & Group II & \\
\hline & & $N=45$ & $N=25$ & $P$ value \\
\hline Age (years) & Mean $\pm S D$ & $53.1 \pm 19.1$ & $59.5 \pm 16.3$ & 0.159 \\
\hline Sex & $\begin{array}{c}\text { Male } \\
\text { Female }\end{array}$ & $\begin{array}{l}29(64.4 \%) \\
16(35.6 \%)\end{array}$ & $\begin{array}{l}17(68 \%) \\
8(32 \%)\end{array}$ & 0.764 \\
\hline Occupation & $\begin{array}{c}\text { Sedentary work } \\
\text { Farmer } \\
\text { Housewife } \\
\text { Worker }\end{array}$ & $\begin{array}{c}7(15.6 \%) \\
11(24.4 \%) \\
12(26.7 \%) \\
15(33.3 \%)\end{array}$ & $\begin{array}{c}1(4 \%) \\
2(8 \%) \\
9(36 \%) \\
13(52 \%)\end{array}$ & 0.125 \\
\hline Residence & $\begin{array}{l}\text { Urban } \\
\text { Rural } \\
\end{array}$ & $\begin{array}{c}9(20 \%) \\
36(80 \%) \\
\end{array}$ & $\begin{array}{l}12(48 \%) \\
13(52 \%) \\
\end{array}$ & $0.014 *$ \\
\hline Smoking & $\begin{array}{l}\text { Non-smoker } \\
\text { Smoker } \\
\text { Ex-smoker } \\
\end{array}$ & $\begin{array}{c}26(57.8 \%) \\
11(24.4 \%) \\
8(17.8 \%) \\
\end{array}$ & $\begin{array}{l}15(60 \%) \\
4(16 \%) \\
6(24 \%) \\
\end{array}$ & 0.651 \\
\hline
\end{tabular}

- Independent samples T test for parametric quantitative data between the two groups

- Chi square (if expected values within cell > 5) or Fisher's exact test (if expected value within cell $<5$ ) for qualitative data between the two groups

- *: Significant level at $\mathrm{P}$ value $<0.05$

The proportion of patients achieving a conclusive positive diagnosis within a particular patient population is defined as diagnostic yield i.e. the likelihood that the diagnostic modality between the 2 cohorts $(88.8 \%$ in the ultrasound cohort vs. $96 \%$ in the thoracoscopy).

Table (2): Comparative statistical analysis between complications of group I and group II

\begin{tabular}{|c|c|c|c|c|}
\hline & & $\begin{array}{c}\text { Group I } \\
\mathrm{N}=45\end{array}$ & $\frac{\text { Group II }}{\mathrm{N}=25}$ & $P$ value \\
\hline $\begin{array}{c}\text { Pain in site of } \\
\text { puncture }\end{array}$ & $\begin{array}{l}\mathrm{No} \\
\mathrm{Yes}\end{array}$ & $\begin{array}{l}29(64.4 \%) \\
16(35.6 \%)\end{array}$ & $\begin{array}{c}6(24 \%) \\
19(76 \%)\end{array}$ & $0.002 *$ \\
\hline $\begin{array}{c}\text { Surgical } \\
\text { emphysema }\end{array}$ & $\begin{array}{l}\mathrm{No} \\
\mathrm{Yes}\end{array}$ & $\begin{array}{c}4(97.8 \%) \\
1(2.2 \%)\end{array}$ & $\begin{array}{c}20(80 \%) \\
5(20 \%)\end{array}$ & $0.020 *$ \\
\hline Empyema & $\begin{array}{l}\mathrm{No} \\
\mathrm{Yes}\end{array}$ & $\begin{array}{c}45(100 \%) \\
0(0 \%)\end{array}$ & $\begin{array}{c}24(96 \%) \\
1(4 \%) \\
\end{array}$ & 0.357 \\
\hline $\begin{array}{c}\text { Surgical wound } \\
\text { infection }\end{array}$ & $\begin{array}{l}\mathrm{No} \\
\mathrm{Yes}\end{array}$ & $\begin{array}{c}45(100 \%) \\
0(0 \%)\end{array}$ & $\begin{array}{c}20(80 \%) \\
5(20 \%)\end{array}$ & $0.004 *$ \\
\hline Bleeding & $\begin{array}{l}\mathrm{No} \\
\mathrm{Yes}\end{array}$ & $\begin{array}{c}44(97.8 \%) \\
1(2.2 \%) \\
\end{array}$ & $\begin{array}{c}24(96 \%) \\
1(4 \%) \\
\end{array}$ & 1 \\
\hline $\begin{array}{l}\text { Failure of full } \\
\text { expansion }\end{array}$ & $\begin{array}{l}\text { No } \\
\text { Yes }\end{array}$ & $\begin{array}{c}45(100 \%) \\
0(0 \%)\end{array}$ & $\begin{array}{c}22(88 \%) \\
3(12 \%)\end{array}$ & $0.042 *$ \\
\hline
\end{tabular}

- $\quad$ Fisher's exact test for qualitative data between the two groups

- *: Significant level at $\mathrm{P}$ value $<0.05$

Table (3): Comparison between Final diagnoses of the two groups

\begin{tabular}{llll}
\hline & & Group I & Group II \\
\cline { 3 - 4 } & & $\mathbf{N}=\mathbf{4 5}$ & $\mathbf{N}=\mathbf{2 5}$ \\
\hline \multirow{4}{*}{ Final } & Malignant tumors & $23(51.1 \%)$ & $19(76 \%)$ \\
diagnosis & Benign tumors & $1(2.2 \%)$ & $0(0 \%)$ \\
& Infection & $13(28.9 \%)$ & $3(12 \%)$ \\
& Inflammation/autoimmune & $3(6.7 \%)$ & $2(8 \%)$ \\
& Nonspecific (Undiagnosed) & $5(11.1 \%)$ & $1(4 \%)$ \\
\hline
\end{tabular}

Malignant (mesothelioma, metastatic adenocarcinoma, lymphoma and metastatic) Benign (pleural fibroma), Infections (Tuberculosis or Para pneumonic) and Inflammation/autoimmune (SLE and vasculitis). 

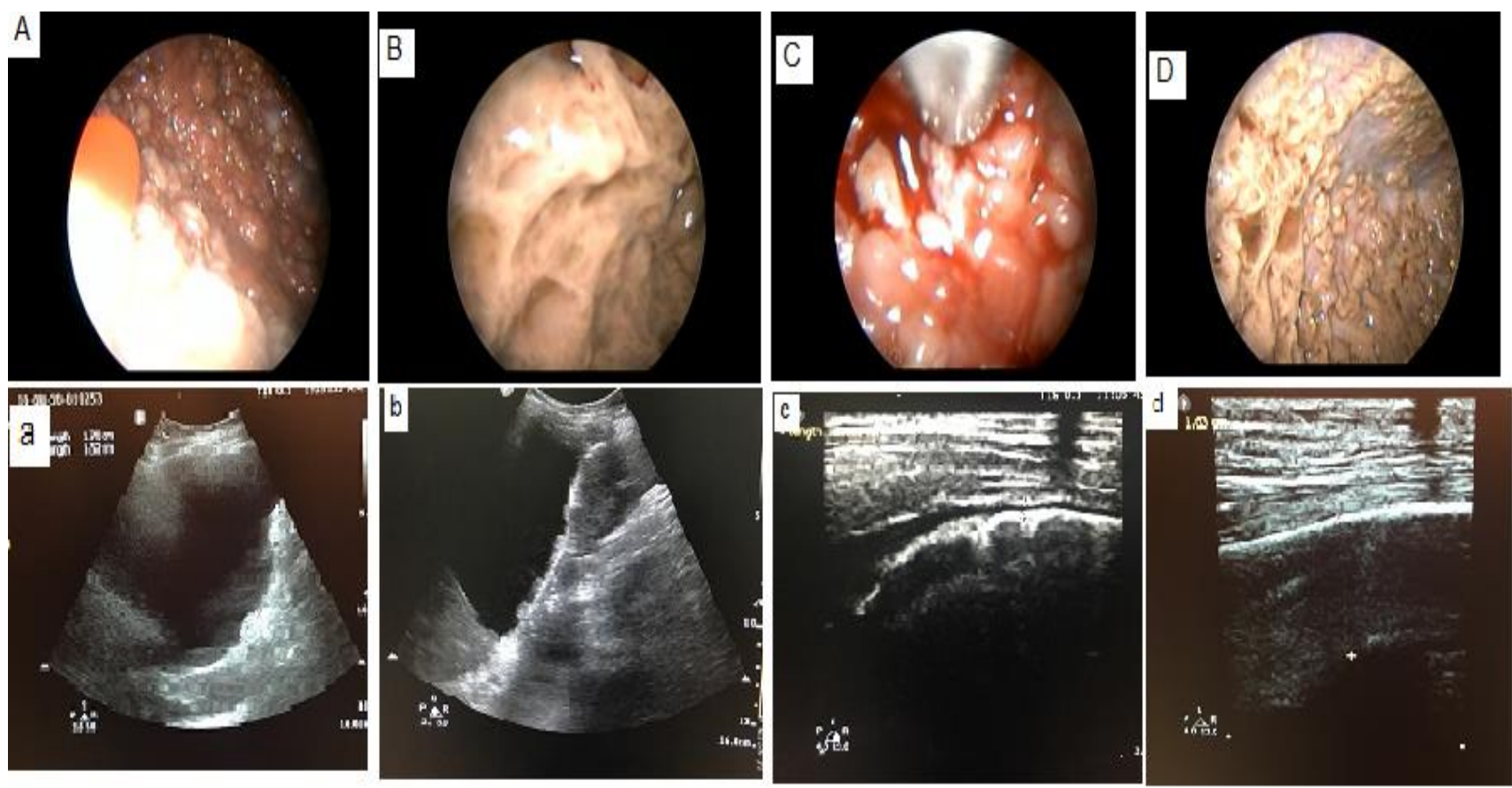

Figure (1) Showed thoracoscopic finding in upper row with corresponding sonar finding in lower row. (A) Abnormal parietal pleura studded with variable size nodules (a) TUS showed two variable size diaphragmatic nodules. (B)Thickened parietal pleura with sign of lymphangiosis (b) thickened diaphragm with variable size nodules. (C) Thoracoscopic forceps during taking biopsy from pleural nodule (c) TUS M-mode showed pleural thickening and nodularity. (D) Studded parietal pleura with whitish fibrin deposition (d) TUS M-mode showed pleural thickening more than $1 \mathrm{~cm}$.

\section{DISCUSSION}

In our study, the diagnostic accuracy and sensitivity for sonar-guided biopsy in idiopathic PE were $88.8 \%$ and $90 \%$ respectively versus diagnostic accuracy and sensitivity of thoracoscopic-guided biopsy were $96 \%$ and $100 \%$ respectively. This is in agreement with Mohamed $\boldsymbol{e t} \boldsymbol{a l} .{ }^{(\mathbf{2 0})}$ who stated that sensitivity of medical thoracoscopy was $100 \%$ and a sensitivity of TUS guided biopsies were $90 \%$, which is supporting our study results. Boutin et al. (21) reported that diagnostic yield result of medical thoracoscopy was $97 \%$, Blanc et al. ${ }^{(22)}$ also reported that medical thoracoscopy was $93.3 \%$ and Sobhy $\boldsymbol{e t}$ al. ${ }^{(23)}$ confirmed that diagnostic results of medical thoracoscopy and TUS-guided biopsies were $95.07 \%$ and $81.24 \%$ respectively.

Chang et $\boldsymbol{a l} .{ }^{(12)}$ found the diagnostic yield of sonar-guided Tru-cut pleural biopsy to be as high as $87 \%$ for all pleural diseases. Zhou et al. (24) demonstrated that thoracoscopic pleural biopsy and ultrasound-guided biopsy provide strong diagnostic yield (> 80\%) but statistically similar for diagnosing pleural effusions following inconclusive thoracentesis and in detecting tuberculous pleurisy.

As regards safety of procedure, our study showed the complications of the two diagnostic methods in details (Table 2). The thoracoscopy cohort displayed overall greater percentages of postprocedural complications, pain in site of puncture is most common complication (76\%). These complications required symptomatic treatment and some resolved spontaneously. In the ultrasound cohort, one case $(2.2 \%)$ resulted in surgical emphysema and pneumothorax. This case required closed thoracic drainage, leading to complete recovery within few days. Also, Zhou et al. ${ }^{(24)}$ stated that thoracoscopy post-procedural complications displayed overall greater percentages compared to TUS-guided biopsy. Most commonly were subcutaneous emphysema $(20 / 98,20 \%)$ and chest pain $(18 / 98,18 \%)$. These complications were also amenable to symptomatic treatment or resolved spontaneously. But In the ultrasound cohort, 4 cases $(4 / 98,4 \%)$ resulted in pneumothorax. Hassanein et al. ${ }^{(25)}$ said that there was no significant difference between both groups as regards complications.

The final diagnostic findings for the two groups were summarized in table (3). Hassanein et al. ${ }^{(25)}$ showed that distribution of diagnoses in cases of group I (MT group); 13 cases (86.5\%) were diagnosed as malignant and 2 cases (13.5\%) as inflammatory lesions and in group II (TUS-guided Abrams needle biopsy group); 8 cases (52.8\%) were diagnosed as malignant and 7 cases $(47.2 \%)$ as inflammatory lesions.

\section{CONCLUSION AND RECOMMENDATIONS}

TUS examination has comparable sensitivity and 
specificity to medical thoracoscopy and allows better assessment of effusion. We recommend firstly, TUS is mandatory before thoracocentasis, pleural biopsy and medical thoracoscopy. Secondly, collections of data from multi experience centres in Egypt to get valuable data about prevalence, most common causes of pleural effusion, most common available diagnostic tool for effusion, safety and complications of different diagnostic tools.

\section{REFERRENCES}

1. Feller-Kopman D (2006): Ultrasound-guided thoracentesis. Chest, 129 (6): 1709-14.

2. Light R (2007): Pleural diseases. Lippincott Williams \& Wilkins.https://www.scirp.org/(S (vtj3fa45qm1ean45vvffcz55))/reference/ReferencesP apers.aspx?ReferenceID $=1828017$

3. Collins T, Sahn S (1987): Thoracocentesis: clinical value, complications, technical problems, and patient experience. Chest, 91 (6): 817-822.

4. Porcel J, Esquerda A, Vives M et al. (2014): Etiology of pleural effusions: analysis of more than 3,000 consecutive thoracenteses. Archivos de Bronconeumología, 50 (5): 161-165.

5. Du Rand I, Maskell N (2010): Introduction and methods: British Thoracic Society Pleural Disease Guideline 2010. Thorax, 65: 1-3.

6. Koegelenberg C, Irusen EM, von GrooteBidlingmaier F et al. (2015): The utility of ultrasound-guided thoracentesis and pleural biopsy in undiagnosed pleural exudates. Thorax, 70 (10): 995-7.

7. Prakash U, Reiman H (1985): Comparison of needle biopsy with cytologic analysis for the evaluation of pleural effusions: Analysis of 414 cases. Mayo Clin Proc., 60: 158-64.

8. Hooper C, Lee $\mathbf{Y}$, Maskell $\mathbf{N}$ et al. (2010): Investigation of a unilateral pleural effusion in adults: British Thoracic Society Pleural Disease Guideline 2010. Thorax, 65: 4-17.

9. Rahman N, Ali N, Brown G et al. (2010): Local anaesthetic thoracoscopy: British Thoracic Society Pleural Disease Guideline 2010. Thorax, 65 (2): 5460.

10. Rahman N, Gleeson F (2008): Image-guided pleural biopsy. Curr Opin Pulm Med., 14 (4): 331-6.

11. Sconfienza L, Mauri G, Grossi $F$ et al. (2013): Pleural and peripheral lung lesions: comparison of US- and CT-guided biopsy. Radiology, 266 (3): 9305.

12. Chang D, Yang P, Luh K et al. (1991): Ultrasoundguided pleural biopsy with Tru-Cut needle. Chest, 100 (5): 1328-33.

13. Hallifax R, Corcoran JP, Ahmed A et al. (2014):
Physician-based ultrasound-guided biopsy for diagnosing pleural disease. Chest, 146 (4): 1001-1006.

14. Koegelenberg C, Bolliger C, Theron J et al. (2010): Direct comparison of the diagnostic yield of ultrasound-assisted Abrams and Tru-Cut needle biopsies for pleural tuberculosis. Thorax, 65 (10): 857 62.

15. Metintas M, Yildirim H, Kaya $T$ et al. (2016): CT Scan-Guided Abrams' Needle Pleural Biopsy versus Ultrasound-Assisted Cutting Needle Pleural Biopsy for Diagnosis in Patients with Pleural Effusion: A Randomized, Controlled Trial. Respiration, 91 (2): 156-63.

16. Seijo L, Sterman D (2001): Interventional pulmonology. N Engl J Med., 344 (10): 740-9.

17. Light $R$ (1995): Pleural diseases 3rd ed., 154-166 William \& Wilkins. Baltimore, MD, Pp: 361. https://doi.org/10.1002/1099-

0496(199606)21:6<398::AID-

PPUL1950210603>3.0.CO;2-H

18. Benamore R, Scott K, Richards CJ et al. (2006): Image-guided pleural biopsy: diagnostic yield and complications. Clinical Radiology, 61 (8): 700-705.

19. Glas A, Lijmer J, Prins M et al. (2003): The diagnostic odds ratio: a single indicator of test performance. J Clin Epidemiol., 56 (11): 1129-35.

20. Mohamed E, Talaat I, Abd Alla A et al. (2013): Diagnosis of exudative pleural effusion using ultrasound guided versus medical thoracoscopic pleural biopsy. Egyptian Journal of Chest Diseases and Tuberculosis, 62 (4): 607-615.

21. Boutin C, Viallat J, Cargnino $P$ et al. (1981): Thoracoscopy in malignant pleural effusions. American Review of Respiratory Disease, 124 (5): 588-592.

22. Blanc F, Atassi K, Bignon J et al. (2002): Diagnostic value of medical thoracoscopy in pleural disease: a 6 year retrospective study. Chest, 121 (5): 1677-1683.

23. Sobhy K, Kamal K, Ahmed $S$ et al. (2017): Ultrasound guided closed pleural biopsy versus medical thoracoscopic pleural biopsy in diagnosis of pleural diseases. Egyptian Journal of Chest Diseases and Tuberculosis, 66 (1): 97-106.

24. Zhou X, Jiang P, Huan $X$ et al. (2018): UltrasoundGuided versus Thoracoscopic Pleural Biopsy for Diagnosing Tuberculous Pleurisy Following Inconclusive Thoracentesis: A Randomized, Controlled Trial. Medical Science Monitor, 24: 723848.

25. Hassanein E, El Ganadya A, El Hoshya M et al. (2017): Comparative study between the use of image guided pleural biopsy using abram's needle and medical thoracoscope in diagnosis of exudative pleural effusion. Egyptian Journal of Chest Diseases and Tuberculosis, 66 (3): 435-440. 